\title{
ÜBER DEN ALKALISCHEN AUFSCHLUSS DES STROHS DURCH STUFENKOCHVERFAHREN
}

\author{
von K. Akagi.
}

(Eingegangen am 9. Dezember 1938)

Unser Versuch diente dem alkalischen Aufschluss des in Japan produzierten Reisstrohs. Das Material wurde nach Entfernung der Knoten unter gewöhnlichem Druck dem $Z$ weistufenkochverfahren unterworfen, d.h. in 1\% iger NaOH Lösung und in einer Mischung von Soda gekocht. Die Tabelle I zeigt den Bestandteil des ungebleichten Zellstoffes bei dieser Reaktion.

\begin{tabular}{|c|c|c|c|}
\hline Bestandteile Kochen & Nr. 18 & Nr. 21 & Nr. 24 \\
\hline $\begin{array}{l}\text { Asche } \ldots \ldots \ldots \ldots \ldots \ldots \\
\alpha \text {-Cellulose } \ldots \ldots \ldots \ldots \ldots \\
\beta \text {-Cellnlose } . . . \ldots \ldots \ldots \ldots \\
\gamma \text {-Cellulose } . . . \ldots \ldots \ldots \ldots \\
\text { Pentosane } . . . \ldots \ldots \ldots \ldots \ldots\end{array}$ & $\begin{array}{r}0.32 \% \\
88.10 \%\end{array}$ & $\begin{array}{l}3.25 \% \\
7.60 \%\end{array}$ & $\begin{array}{c}-\overline{-} \\
-51.56 \% \\
- \\
-\end{array}$ \\
\hline $\begin{array}{l}\mathrm{SiO}_{2} \text { in Asche } . . . . . . . . \\
\text { Gesamtausbente ....... }\end{array}$ & - & $\begin{array}{l}62.33 \% \\
23 \%\end{array}$ & $\begin{array}{l}60.61 \% \\
23 \%\end{array}$ \\
\hline
\end{tabular}

Wie oben angegeben, wird das in Jnpan produzierte Reisstroh beim Sodaverfahren unter gewöhnlichem Druck leicht zum Kochen gebracht. Die Farhe das Reaktionszellatoffes ist vor dem Bleichen hell (licht), und zwar beinahe weiss, und der Bestandteil desselben zeigt ausser der Aschenmenge ein gutes Resultat.

Aber der Strohzellstoff enthält ausser den Bastfasern mehr oder weniger Parenchymzellen und Kieselkörper, und bei Anwendung des Viskoseverfahren ergeben sich zahlreiche ungelöste Körper.

Heute ist dieser Strohzellstoff als Faserstoff fast wertlos.

Der Verfasser hat ähnliche Versuche mit Weizenstroh unternommen, dessen Zellstoff besser ist als der des Reisstrohs. Aber der Weizenstrohzellstoff ist wohl im Vergleich zum letzteren in geringerer Quntität in Japan vorhanden. 